\title{
Strates
}

STRATES Matériaux pour la recherche en sciences sociales

$4 \mid 1989$

Dossier : images réfléchies. Paroles d'un paysan révolutionnaire

\section{On est prié de reprendre son cœur au vestiaire}

\section{Michèle Petit}

\section{(2) OpenEdition \\ Journals}

Édition électronique

URL : http://journals.openedition.org/strates/4702

DOI : $10.4000 /$ strates.4702

ISSN : 1777-5442

Éditeur

Laboratoire Ladyss

Édition imprimée

Date de publication : 31 décembre 1989

ISSN : 0768-8067

Référence électronique

Michèle Petit, « On est prié de reprendre son cœur au vestiaire », Strates [En ligne], 4 | 1989, mis en ligne le 19 mai 2008, consulté le 08 septembre 2020. URL : http://journals.openedition.org/strates/ 4702 ; DOI : https://doi.org/10.4000/strates.4702

Ce document a été généré automatiquement le 8 septembre 2020

Tous droits réservés 


\title{
On est prié de reprendre son cœur au vestiaire
}

\author{
Michèle Petit
}

1 «On est prié de fermer les yeux » était-il écrit dans un rêve de Freud. On est prié de laisser son cœur au vestiaire, quand on entreprend d'aller de par le monde voir, savamment, doctement, à quoi ressemblent les humains et leurs sociétés. Mais quelquefois le cœur, ce sauvage, fait retour sur la pointe des pattes, tel un chat cent fois repoussé et qui, par le biais du fauteuil, réussit quand même à s'installer sur les genoux du maître distrait dans ses travaux. Alors le maître se prend à rêver. Et griffonne un poème, ou un dessin. Vite effacés. Mais dont il reste parfois une trace dans l'article sérieux qu'il rédigeait.

2 Parmi les brouillons chiffonnés au fond du panier, dans les marges des rapports scientifiques, soigneusement blanchies à la chaux du Tipp-Ex, il y a ainsi ce que chacun fait de ses états d'âme, dans ces quelques instants où il vit en bonne intelligence avec eux. A les refouler du mieux qu'il peut, il s'expose au risque que ses travaux ne se dessèchent de plus en plus, tels des papillons ennuyeux dans leurs boîtes. Et le chercheur devient triste. Quelquefois il s'en sort par les ruses d'une double vie et par exemple, histoire de retrouver un peu de lui-même, il publie des nouvelles ou des photographies sous un pseudonyme, lassé qu'il était de tenir ses émotions éloignées avec des pincettes, comme si c'était des tisons. A force, il avait bien cru que cette saleté allait finir par s'éteindre, mais pour lui ça n'avait pas marché. Alors il les avait ainsi logées dans une écurie spéciale, et il les faisait courir de temps en temps. Ou il s'autorise un peu à laisser venir hasards, aventures, désirs et libres associations, ou quelques simples impressions, là même où il est censé n'être que raison, et c'est évidemment là que quelquefois, tel Picasso, il trouve plutôt que de chercher.

On gagnerait donc à laisser le cœur vagabonder plus librement, et le chercheur écouter sa sensation. Or c'est souvent seulement quand ils sont âgés et très érudits que les savants se permettent enfin de laisser un peu la bride sur le cou à leurs fantaisies. Autrement, sans doute n'auraient-ils jamais pu entrer dans l'institution, ou y auraientils pris moins de galons. Même les femmes, qui ont plus de dons pour ne pas se croire 
seulement pure raison, une fois dans le sérail mettent, hélas, souvent, un zèle redoublé à se marcher sur le corps - lequel se défend comme il peut - afin de bien s'aligner dans le rang. Pas de cœur, pas de sexe.

4 Mais si ladite institution veille aux grains de sable qui pourraient rayer ses pavés, le chercheur doit surtout affronter l'ennemi intérieur, le chevalier en armes, tout cliquetant dans son âme. Car, contrairement à ce que croient les bonnes gens qui se moquent de ces planqués de scientifiques qui, hormis quelques héros, seraient payés à vie pour chercher tranquillement, ceux-ci mènent une vie dangereuse, faite de transgressions et d'inhibitions, qu'ils affrontent tant bien que mal, quelquefois avec gaieté, souvent en claquant des dents, ou en mâchouillant leur stylo pour se calmer. C'est dans la nature de la pulsion épistémophile, et il n'est que de relire Mélanie Klein ("Contribution à la théorie de l'inhibition intellectuelle») pour prendre la mesure des enjeux.

D'ailleurs dans Tintin, les savants étaient bien mal traités: sanglés dans leurs lits d'hôpital, tant ils se convulsaient, tandis qu'à l'autre bout du monde l'Inca transperçait de ses flèches leurs effigies. Juste retour des choses : ne transperçaient-ils pas, de leurs outils, les corps et les pays qu'ils prétendaient connaître? Possession sauvage qui se retournait contre eux, réduits à leur tour à s'exhiber et à faire le grand arc, comme les hystériques de Charcot. Le corps que refoulait la science revenait au galop, et en rajoutait dans la danse de Saint-Guy.

6 Vieille histoire... de l'Arbre de la Science à ces archéologues, l'univers ne raffolerait pas d'être compris, et il y aurait toujours profanation à creuser le ventre des pyramides, ou à aller y voir, sur des terres faites "terrains ", où l'on fore à coups de concepts en fer blanc qui font s'évanouir ce que l'on découvre, telles les peintures antiques s'effaçant aussitôt qu'elles aient été trouvées dans la Rome de Fellini.

7 Donc le savant expie : Lévi-Strauss haïssait les voyages qu'il faisait, et croquait des chenilles avec dégoût. Ce dont nous nous souvînmes, en mission en Asie, invitées à déguster, devant dix Chinois souriants, des pattes d'iguanes bouillies, et la tête d'un poulet à laquelle manquait un œil, qui sans cesse remontait à la surface du bol, toujours renaissant malgré mes coups de baguettes enfouisseurs. Toujours l'œil était dans le riz et me regardait, l'air de dire : "Tu voulais te les mettre sous la dent, ces Chinois? Eh bien mange!» Ainsi est-on puni par là où l'on pensait pêcher. Bien élevées, nous avalions. La semaine durant, nous enquêtions, comme des maniaques. Et le dimanche, nous allions là où vont les touristes: au jardin botanique, au zoo, dans les champs d'orchidées. Et des oiseaux de rêve, des fleurs à perte de vue, des animaux inconnus. Et un pauvre pingouin, otage sous les tropiques. Et au-dessus un immense filet, tant cet Etat était fou qu'il enfermait même ses réserves d'oiseaux... Nous y coincions, jusqu'au dimanche suivant, nos émotions, et allions les visiter, prisonnières qui étaient là à ronger tristement les barreaux de leurs cages.

Et puis quelquefois, ces pays, on s'y fondait, sans en mourir. Dans les trains de Hongkong à Canton aux rideaux de dentelle, ou dans les parcelles de forêts vierges de Bukit Timah, ou dans cet autobus, qui me ramenait le soir d'un savant institut, virait tout d'un coup, grimpait dans une colline, comme si le chauffeur, tel Amadis Dudu dans L'Automne à Pékin, faisait une fugue, et nous ravissait. Toutes portes ouvertes, le bus montait parmi les lianes immenses, comme dans ces contes de fée où la végétation pousse soudainement, arbres géants, nos pauvres plantes de salon, philodendrons ou 
caoutchoucs, s'agrippant là à des troncs de trente mètres. Mais toujours la jungle finissait par se cogner dans les gratte-ciel.

De vrais carnets de terrain devraient-ils parler de choses comme ça? Et aborder le vaste chapitre des interdits, qui sont aussi entre les lignes des écrits académiques, et surtout dans leurs blancs? Et en dire un peu plus, enfin, sur le travail scientifique, son processus, ses fausses pistes, ses ratés, ses trouvailles, ses plaisirs, ses à-côtés?

10 Les ethnologues, chez qui l'écrivain ne dort souvent que d'un œil, et qui ont beaucoup beaucoup d'états d'âme, ne se sont pas privés de les exhiber, plutôt sur le mode mélancolique - toujours cette histoire d'expiation-. Chez les grands ancêtres des géographes, c'était plutôt l'occasion de descriptions lyriques. Leurs descendants se sont employés à se faire une vertu de scientificité en jetant tout cela aux orties. Ça n'interdit pas, sans tomber dans les délices du subjectivisme, de reprendre son cœur au vestiaire. Après tout, il n'y a pas de raison de désespérer : l'amour, ce serait comme la bicyclette : même si on n'en fait pas usage pendant longtemps, il paraît que ça revient tout seul.

\section{RÉSUMÉS}

Défense et illustration du savant écoutant son cœur vagabonder et trembler...

You are invited to get back your heart from the vestibule

Truthfull testimony of the researcher allowing herself to listen to her wandering and thrilling heart.

\section{INDEX}

Mots-clés : pulsion épistémophile

Keywords : urge to investigate

\section{AUTEUR}

\section{MICHÈLE PETIT}

Ingénieur au CNRS, elle est rattachée au Laboratoire STRATES. Elle poursuit actuellement des recherches sur les entrepreneurs de plusieurs pays d'Asie (Taiwan, Singapour, Hong Kong). 